\title{
Um plano nacional de capacitação financeira: o caso brasileiro *
}

\author{
Fernando Pereira ** \\ Anderson Cavalcante ${ }^{* * *}$ \\ Marco Crocco ${ }^{* * * *}$
}

\section{Resumo}

Este artigo discute formatos desejáveis para um plano nacional de capacitação financeira, a partir da experiência brasileira. As propostas convencionais usualmente dão excessiva importância à educação financeira, sob justificativa de que a transferência de conhecimento e informação é a melhor forma de promover alfabetização, capacitação e bem-estar financeiro. A análise crítica desta proposta mostra, porém, que ela é inadequada, pois: i) é imperativo incluir o ambiente em que as decisões financeiras são tomadas e; ii) a qualificação financeira não pode se dar prioritariamente via transferência de conhecimento, mas pelo aconselhamento financeiro provido por especialistas independentes.

Palavras-chave: Capacitação financeira; Educação financeira; Regulação do sistema financeiro; Sistema de proteção ao consumidor financeiro; Abordagem institucionalista; Índice de capacitação financeira.

\begin{abstract}
A national financial capability plan: the Brazilian case

This paper discusses desirable formats for a financial capability plan from the perspective of the Brazilian experience. The conventional proposal has usually been to much focused on financial education, arguing that transfer of knowledge and information is the best way to promote financial literacy, financial capability and wellbeing. However, the critical analysis of this proposal shows that it is inadequate because: (i) the treatment must deal with the environment in which financial decisions are taken, and; (ii) financial qualification can not be achieved through primary education, but through financial advice provided by independent experts.
\end{abstract}

Keywords: Financial capability; Financial education; Financial system regulation; Protection system to financial consumers institutionalist approach; Financial capability index.

JEL G02, G10, G19, G2.

\section{Introdução}

No último decênio, propostas de política pública de educação financeira, para a população em geral, têm recebido amplo apoio por parte de diferentes atores no cenário internacional com destaque para: organismos multilaterais, instituições financeiras, autoridades

\footnotetext{
* Artigo recebido em 28 de março de 2017 e aprovado em 24 de março de 2018.

${ }^{* *}$ Professor do Instituto de Ciências Sociais Aplicadas da Universidade Federal de Alfenas (ICSA/Unifal), Alfenas, MG, Brasil. E-mail: fernando.pereira@unifal-mg.edu.br.

${ }^{* * *}$ Professor do Centro de Desenvolvimento e Planejamento Regional da Universidade Federal de Minas Gerais (Cedeplar/UFMG), Belo Horizonte, MG, Brasil. E-mail: atmc@ cedeplar.ufmg.br.

${ }^{* * * *}$ Professor do Centro de Desenvolvimento e Planejamento Regional da Universidade Federal de Minas Gerais (Cedeplar/UFMG), Belo Horizonte, MG, Brasil. E-mail: crocco@ cedeplar.ufmg.br.
} 
governamentais, instituições acadêmicas e de pesquisa e fundações e entidades do terceiro setor. Esse cenário tem se refletido também no Brasil, resultando na elaboração e execução da Estratégia Nacional de Educação Financeira (Enef) e constituição do Comitê Nacional de Educação Financeira (Conef), em parceria firmada no último decênio pelo governo brasileiro junto a entidades representativas do setor financeiro e da sociedade civil.

$\mathrm{O}$ argumento principal em defesa da educação financeira é que ela impulsionaria a capacitação financeira das famílias, por meio da transferência de conhecimentos e informações sobre o correto gerenciamento das finanças pessoais, e também sobre o uso da variedade de oferta de produtos e serviços financeiros disponíveis no mercado. Dentro dessa ótica, a educação financeira, ao empoderar o cidadão, fortalece a autorregulamentação de mercado e, portanto, minimiza (ou mesmo dispensa) estratégias de regulamentação e proteção ao consumidor financeiro.

Embora se reconheça sua importância, entende-se que a simples promoção da educação financeira, de forma isolada, não vai qualificar as decisões das famílias, considerando a atual natureza do sistema financeiro. Ao contrário, caso não se foque o próprio sistema e sua condição de promover uma inclusão financeira adequada e protegida, o resultado obtido pela estratégia será contraproducente para promoção da capacitação financeira.

Esse artigo propõe um plano alternativo de capacitação financeira, desenhado para o caso brasileiro. Isso é relevante pois, até onde sabemos, não há, na literatura nacional, qualquer discussão crítica sobre uma proposta similar. Por outro lado, a literatura internacional, via de regra, tende a utilizar instrumentos comuns a países desenvolvidos, que não podem simplesmente serem replicados em qualquer país. A partir daí, a inovação de nossa proposta passa a ser o tratamento da capacitação financeira com a inclusão do ambiente social, econômico e financeiro, reduzindo a responsabilidade dada ao cidadão comum. Para isso, o artigo está dividido em quatro seções: a primeira introduz os principais conceitos a serem tratados; a segunda analisa criticamente os principais traços da proposta "convencional" de educação e capacitação financeira, por meio de abordagem institucionalista; a terceira apresenta o plano de capacitação financeira para o caso brasileiro, assim como uma estimativa orçamentária preliminar; e a última seção aponta as principais conclusões.

\section{Educação e capacitação financeira: definições}

Para iniciar a exposição, a seção define de forma mais precisa os conceitos a serem utilizados. Isso se faz necessário pois parte destes são ainda recentes, sendo muitas vezes apresentados na literatura de modo confuso e inapropriado (Hassan et al., 2008).

Em primeiro lugar, educação financeira deve ser entendida como uma ação de instrução, que envolve treinamento e ensinamento, e visa assegurar conhecimento e habilidade para entender termos e conceitos financeiros, saber manipulá-los e utilizá-los, compreendendo suas relações. 
Um plano nacional de capacitação financeira: o caso brasileiro

Isso corresponde a temas ligados às finanças pessoais, como conceitos, relações causais, manejo de ferramentas de estatística e matemática financeira, práticas financeiras cotidianas, descrição geral do mercado financeiro e dos principais produtos e serviços e riscos e incertezas relacionados às finanças pessoais. Além desses, a educação financeira deve contemplar ações complementares, referentes à obtenção de informações e conselhos (atualizados, detalhados e confiáveis) sobre: i) produtos e serviços financeiros disponíveis, em comparação aos ativos reais; ii) acesso a bases de dados, fontes de informação e de opinião sobre o estado atual e tendências futuras (séries históricas e projeções); iii) conflito de interesses existentes na vida financeira e; iv) sistema vigente de proteção ao consumidor financeiro e, principalmente, de formas de acesso a esse tipo de profissional ou instituição, para fins preventivos ou corretivos.

O conteúdo coberto pela educação financeira é claramente dinâmico e requer atualização e reeducação, para poder ser de fato apreendido pelos participantes. Adicionalmente, por estar voltado a um público heterogêneo e não especializado, este deve ser dividido em nichos, e seu conteúdo não pode ser aprofundado (a não ser em casos especiais), dada a natural falta de tempo, interesse ou competência técnica dos participantes, como embasado por inúmeras pesquisas empíricas (Pereira, 2015). Finalmente, deve-se assumir que a natureza da educação financeira tem estrutura unidirecional, na qual um ou mais instrutores leciona para um grupo de participantes (via aulas, seminários, workshops, práticas expositivas ou interativas, ou atividades lúdicas), sem envolver tratamento personalizado (além do esclarecimento de dúvidas pontuais) (Hassan et al., 2008).

Essa última característica é relevante para diferenciar a educação do aconselhamento financeiro, muitas vezes tratados como conceitos similares na literatura especializada. $\mathrm{O}$ aconselhamento financeiro envolve orientação ou sugestão feita por especialista sobre uma determinada decisão, com base em um caso particular do requerente. Não há transferência de conhecimento, mas a sugestão ou indicação de ações ou de um comportamento, em resposta a determinadas circunstâncias que podem ser acompanhadas ao longo do tempo. Como resultado, o requerente irá ou não aceitar a sugestão em sua decisão financeira, com base no grau de confiança que tem no especialista, independentemente de entender as motivações técnicas de tal conselho (assim como em consultas a médico ou advogado), ainda que possa ter havido explicações conceituais e conjunturais durante essa exposição (Hassan et al., 2008; Sherraden, 2010; Willis, 2008).

O quadro de aconselhamento financeiro incorpora uma diversidade de tratamentos que podem ser mais profundos ou genéricos, e estarem ou não associados ao consumo de um determinado produto ou prática financeira (Thoresen, 2008). Para facilitar essa diferenciação, define-se o conceito de consultor financeiro independente (CFI) (tratado na terceira seção), não vinculado a instituições financeiras, de modo que seu conselho ou sugestão não esteja voltado para o consumo de determinado produto ou serviço, em contraste com um profissional de mercado (banco, corretora ou seguradora). 
O quarto conceito é a alfabetização financeira. Este termo envolve conhecimento teórico acumulado sobre finanças pessoais, que abrange conceitos e termos genéricos, relações causais, acesso e manipulação de variáveis financeiras. A alfabetização financeira está relacionada à capacidade de leitura, compreensão, análise e comunicação de temas ligados às finanças pessoais, sem lidar com decisões práticas. A educação financeira impacta diretamente na alfabetização financeira, justamente por envolver transferência de conhecimentos e informações sobre acesso a outras fontes externas (Servon; Kaestner, 2008; World Bank, 2013).

Por fim, o conceito de capacitação financeira será utilizado aqui de forma diferente de grande parte da literatura especializada. Originalmente, tal conceito, desenvolvido por autoridades e pesquisadores do Reino Unido, é descrito como um indicador de conhecimento prático, habilidade e atitude para lidar com decisões que promovam o bem-estar financeiro. Portanto, espera-se, segundo tal perspectiva, que uma pessoa capacitada financeiramente esteja em condições não apenas de absorver, comunicar e analisar temas de finanças pessoais, mas também de tomar decisões financeiras que contribuam para ganhos de bem-estar financeiro (HM Treasury, 2007; Financial Services Authority, 2005).

Entretanto, entende-se que o conceito de capacitação financeira não pode se limitar a descrever as características e qualificações individuais, sem avaliar o ambiente social, econômico, financeiro e jurídico no qual este indivíduo está inserido - justamente pois esse ambiente pode ser restritivo ou inadequado. Deste modo, o conceito de capacitação financeira deve considerar requisitos mínimos de renda e de inclusão financeira, para que as famílias possam efetivamente tomar as decisões adequadas para seu bem-estar financeiro. Na prática, o conceito de capacitação financeira utilizado neste artigo assume a natureza das capabilities, desenvolvidas por Amartya Sen e Martha Nussbaum, de forma a considerar não apenas as potencialidades e qualificações individuais, mas o ambiente socioeconômico e a configuração do sistema financeiro, seguindo sugestões já apontadas por Sherraden (2010).

\section{Análise crítica da proposta convencional de educação financeira}

\subsection{A proposta convencional de educação financeira: teoria e prática}

Conforme já apontado, a educação financeira de pessoas comuns vem sendo defendida como um instrumento de política pública universal de promoção da capacitação financeira, por parte um conjunto amplo e heterogêneo de atores, o que se traduz na Enef ${ }^{1}$, no caso brasileiro (Lusardi, 2008; Martin, 2007; Russia’s G20 Presidency; OECD, 2013).

Embora singularmente tais propostas possam apresentar particularidades, é possível identificar um núcleo comum, razão pela qual serão denominadas "abordagem convencional de educação financeira". Em geral, três são os elementos consensuais dessa abordagem:

(1) A Enef (Estratégia Nacional de Educação Financeira), criada pelo Decreto Federal 7.397/2010, é uma articulação entre governo e organizações da sociedade civil, com o objetivo de promover ações de educação financeira no país. Maiores detalhes podem ser encontrados em: http://www.vidaedinheiro.gov.br/ e http://www.bcb.gov.br/pre/pef/port/Estrategia_Nacional_Educacao_Financeira_ENEF.pdf. Acesso em: 5 nov. 2016. 
Um plano nacional de capacitação financeira: o caso brasileiro

primeiro, há um cenário generalizado de baixa alfabetização financeira na sociedade contemporânea, o que atinge proporções extremas para determinados nichos sociodemográficos (mulheres, idosos, pobres, pouco educados e negros); segundo, essa baixa alfabetização encontra-se estatisticamente correlacionada a comportamentos financeiros tidos como "inadequados" (não poupam e não usam os melhores produtos e serviços financeiros), assim como ao baixo desempenho financeiro (não acumulam patrimônio) e; terceiro, o pressuposto de que a educação financeira promove alfabetização e capacitação financeira, o que se traduz em comportamentos considerados "adequados" e em consequentes ganhos de bem-estar financeiro, cujos efeitos tendem a se estender para a maior estabilidade do próprio mercado.

O pressuposto teórico por trás desta lógica é que as pessoas se comportam prioritariamente com base em conhecimentos e informações racionais, em prol do bem-estar financeiro. Desta forma, assume-se que a educação financeira, ao transferir conhecimento e informações, promoverá a capacitação financeira, que se reflete em decisões mais acertadas, e, consequentemente, no melhor desempenho financeiro pessoal. Além disso, ao empoderar o consumidor, a educação financeira promove a autorregulamentação de mercado, resultando em benefícios para o sistema financeiro como um todo (Braunstein; Welch, 2002; O'Connell, 2007).

Em termos mais objetivos, o argumento convencional é que a educação financeira vai conscientizar os indivíduos quanto à necessidade de assumirem um comportamento "adequado", de planejamento e adoção de melhores formas de administração do orçamento e finanças domésticos, nas formas de gastos, poupança/seguro, investimento e obtenção de renda. Ao mesmo tempo, saberão distinguir despesas essenciais das desnecessárias (com redução ou corte dessas) e estarão atentos ao planejamento patrimonial e aos gastos que compõem o ciclo de vida familiar, avaliando as melhores formas de gastos/alocação (se é ou não conveniente obter um financiamento), sem comprometer renda futura e capacidade de endividamento. Além disso, saberão fazer uso de produtos e serviços financeiros disponíveis no mercado, serão disciplinadas para se tornar poupadoras da melhor forma possível (aliando rentabilidade, risco e grau de liquidez), estarão atentos ao contratar planos previdenciários e seguros para absorver a possível ocorrência de choques financeiros previstos ou imprevistos (desempregos, mortes, doenças graves, acidentes naturais ou queda abrupta da renda). Finalmente, serão aptos para escolher as melhores formas de obtenção de renda, avaliando as formas mais adequadas de se inserir no mercado de trabalho (Kempson; Atkinson; Pilley, 2004).

Apesar do otimismo manifestado pelos defensores dessa proposta, na prática, as iniciativas de educação financeira têm resultados muito limitados, o que é reconhecido mesmo dentre seus apoiadores (Lusardi, 2008; Mandell, 2006). As justificativas para esse mau desempenho seriam, de um lado, a dimensão do problema da baixa alfabetização financeira da população, o que demandaria um trabalho mais extenso de nivelamento. De outro lado, a carga horária e, por consequência, o conteúdo das iniciativas são modestos, o que tende a gerar 
resultados insuficientes ou até contraditórios, como constatado por pesquisas de avaliação dessas experiências (Pereira, 2015).

Ainda assim, a expectativa dos atores que sustentam a abordagem convencional é que a continuidade e o aprofundamento das iniciativas de educação financeira poderão promover resultados futuros expressivos. No entanto, como será apresentado na sequência, os problemas da educação financeira não são apenas decorrentes da sua aplicabilidade prática, que supostamente poderiam ser superados, mas são também de natureza teórica.

\subsection{A análise crítica institucionalista da educação financeira convencional}

A proposta convencional de educação e capacitação financeira vem recebendo críticas de diversos autores no último decênio, questionando sua lógica e pressupostos básicos. Dentre essas, esse artigo destaca autores denominados institucionalistas, cuja análise está focada não em indivíduos isolados, mas integrantes de um sistema socioeconômico, financeiro e jurídico completo. Para os institucionalistas, isso se faz necessário, pois a natureza desse sistema pode estabelecer limites reais a uma vida financeira.

Em uma primeira instância, os institucionalistas assumiram resultados de estudos behavioristas (comportamentais) para criticar o pressuposto convencional de que as decisões humanas são primordialmente racionais, coerentes e abastecidas por conhecimentos e informações dadas. De fato, desde o final dos anos 1970, pesquisas empíricas behavioristas apontam a presença de uma série de vieses que podem influenciar e gerar decisões muito diferentes desse pressuposto. Esse é o caso, dentre outros, da presença de fatores como procrastinação, ponto de referência, aversão a perdas, contabilidade mental, aversão ao arrependimento, sobrecarga de informação, otimismo e autoconfiança (Kahneman; Tversky, 1979; Meza; Irlenbusch; Reyniers, 2008; Teixeira; Tabak; Cajueiro, 2015), que influenciam as decisões pessoais, em uma ampla gama de contextos e formas, nem sempre controláveis.

Assumindo essa lógica teórica, há o natural questionamento sobre a capacidade da educação financeira em promover mudanças no comportamento pessoal pró bem-estar financeiro, ainda que assumindo que os conhecimentos e informações oferecidos sejam completos e suficientes.

Apesar de contundentes, tais críticas são apenas parciais, pois a análise behaviorista pura aborda o indivíduo de forma isolada e abstrata. Como resultado, a influência dos vieses comportamentais poderia, em teoria, ser minimizada ou mesmo eliminada por outras ações contrárias, também de natureza abstrata. Entretanto, a situação se torna mais complicada com a contextualização do ambiente socioeconômico e financeiro concreto, marcado pela complexidade, instabilidade, conflito de interesses e desequilíbrio de forças presentes no sistema financeiro, em que tais conhecimentos e informações necessárias para uma tomada de decisão podem, quando existirem, não estarem ao alcance de todo o público. 
Um plano nacional de capacitação financeira: o caso brasileiro

Na prática, o ciclo de vida das famílias envolve decisões financeiras cada vez mais complexas e instáveis, principalmente quando considerado o cenário de enfraquecimento das instituições do Estado de bem-estar social, assim como da legislação trabalhista e previdenciária, cujo auge se deu nos países desenvolvidos no período 1945-75. Adicionalmente, a relação das famílias com o mercado financeiro é também muito complexa e instável, em decorrência do aprofundamento do processo de financeirização ocorrido desde o final dos anos 1970, cujo resultado tem sido a transferência de parte do risco operacional para as famílias consumidoras, em um contexto marcado por ciclos de instabilidade (Coutinho; Belluzzo, 2004; Gloukoviezoff, 2006).

Em consequência, famílias com certa estabilidade de renda presente e futura representam casos cada vez menos comuns, o mesmo ocorrendo com a disponibilidade da oferta de serviços de saúde e educação como bens públicos gratuitos. Deve-se esclarecer que tal instabilidade de renda familiar não pode ser simplesmente compensada pelo acesso a bens e serviços financeiros privados (como é o caso de seguros, fundos de investimento e planos previdenciários). Isso porque tais produtos envolvem grande parcela de risco não-calculável ou mesmo não antecipável, principalmente para intervalos de longo prazo (como é o caso das decisões previdenciárias), em que o ciclo econômico pode sofrer reversões, tornando insustentáveis decisões que foram consideradas "adequadas" no ciclo anterior (Froud et al., 2009; Pereira, 2015).

Por fim, as questões do conflito de interesses e do desequilíbrio de forças entre instituições financeiras e as famílias exercem função central sobre a capacitação financeira. É sabido que as relações entre consumidores e ofertantes (particularmente o mercado financeiro) não são isentas de conflito de interesses. No regime de mercado capitalista, empresas e instituições financeiras querem vender, estimular a cultura de consumo e realizar lucros, e esse interesse não necessariamente harmoniza com os objetivos de bem-estar financeiro dos consumidores. Por outro lado, o desequilíbrio de porte cria um ambiente no qual as empresas atuam de forma ativa, selecionando seus clientes e o modo de relacionamento, enquanto os clientes assumem uma condição muito mais limitada de escolha (Dymski, 2007; Gloukoviezoff, 2006) ${ }^{2}$. A combinação de conflito de interesses e desequilíbrio de forças permite que as empresas e instituições detenham grande poder de exploração dos vieses comportamentais, expostos pelos behavioristas, a fim de obter ganhos de mercado, em detrimento do bem-estar dos seus clientes.

Portanto, segundo a análise crítica institucionalista, a simples qualificação educacional financeira, ainda que completa e de qualidade, segundo os padrões da abordagem convencional, seria inadequada para assegurar a capacitação financeira de um indivíduo,

(2) Um exemplo de condição limitada é a segmentação de clientes feita pelas instituições financeiras que, grosso modo, assume a seguinte forma: os ricos (superincluídos) têm acesso aos melhores profissionais e aos melhores produtos e serviços, enquanto os pobres ("marginalmente incluídos") são atendidos apenas de forma impessoal ou por vendedores de produtos caros e qualidade duvidosa. Esses últimos são clientes de "curto prazo", quando não há a preocupação da instituição financeira por um prazo mais longo (Dymski, 2007; Crocco; Santos; Figueiredo, 2013). 
principalmente quando feita de modo isolado. Pelo modo com que a educação financeira convencional é apresentada na literatura (ver primeira seção), os problemas levantados pelos institucionalistas (instabilidade, complexidade, conflito de interesses e desequilíbrio de forças) são totalmente ignorados (o único aspecto que vem sendo reconhecido pela literatura convencional são os vieses comportamentais puros, descontextualizados da realidade empírica). Isso gera uma falsa percepção de que a educação financeira promoverá o bem-estar financeiro dos seus participantes, o que, na prática, pode estimular vieses comportamentais inadequados, como otimismo e autoconfiança excessiva e "sobrecarga de informações", que tendem a gerar resultados opostos aos esperados (Cain; Loewenstein; Moore, 2005; Pereira, 2015; Slovic; Fischhoff; Lichtenstein, 2001).

\section{Proposta de plano nacional de capacitação financeira para o Brasil (PNCF)}

O plano nacional de capacitação financeira (PNCF) para as famílias brasileiras proposto nesta seção busca superar os problemas da atual Enef e seu foco predominante sobre a educação financeira. O plano deve, inicialmente, reestruturar a oferta do setor financeiro às famílias, através de diretrizes de regulamentação e do sistema de proteção de direito do consumidor, com foco na simplicidade, transparência e na responsabilização compartilhada pelo consumo dos produtos financeiros. A justificativa é que, na sua ausência, o impacto do tratamento educacional das famílias seria insignificante.

Em um segundo momento (após montagem, equipamento e treinamento de toda a estrutura pedagógica e de aconselhamento), o plano operará ações de qualificação, orientação e informação das famílias, através de etapas distintas de educação e aconselhamento financeiro. A educação financeira deverá cumprir objetivos de alfabetização básica, como simples nivelador. $\mathrm{O}$ aconselhamento, por outro lado, será provido por especialistas independentes e lidará com questões mais complexas da vida financeira das famílias, através de informação e orientação, com possível acompanhamento e supervisão dos casos mais graves.

\subsection{Regulamentação e Sistema de Proteção ao consumidor financeiro}

Conforme exposto, a promoção da capacitação financeira pressupõe a existência de um ambiente financeiro com normas legais e regulamentadoras que protejam os indivíduos consumidores, de possíveis comportamentos indevidos por parte das instituições provedoras de produtos ou serviços financeiros (como práticas abusivas, enganosas e predatórias, as vezes acompanhadas por exploração de vieses comportamentais), além de parcela dos riscos involuntários envolvidos no consumo de produtos financeiros.

Com esse objetivo, propõe-se cinco diretrizes de regulamentação financeira que devem compor o sistema de proteção vigente no país, em complemento à lei 8.078/1990, do Código de Defesa do Consumidor (CDC). Para formulação dessas, além da revisão da literatura de direito do consumidor financeiro, foi incorporada a análise do Projeto de Lei do Senado (PLS) 283/2012 (remetido à Câmara dos Deputados em 04/11/2015, onde tramita como Projeto 
Um plano nacional de capacitação financeira: o caso brasileiro

de Lei (PL) 3515/2015), que prevê atualização do CDC, contemplando ações de prevenção e tratamento de superendividamento das famílias e que prevê, inclusive, ações de educação financeira.

A primeira diretriz é a obrigatoriedade das instituições provedoras financeiras em divulgar informações que descrevam, com clareza, seus produtos e serviços, seja em publicidade ou em contrato para prévia análise do consumidor, a fim de subsidiar a escolha deste. A justificativa é que, na prática, consumidores não sabem lidar com a complexidade e podem ser induzidos a erros quando expostos a informações dúbias e relativamente difíceis, ainda que completas (Barr, 2005; HM Treasury, 2007).

Portanto, segundo tal diretriz, essas instituições devem especificar, seja em material publicitário ou contratual, todas as características de seus produtos e serviços, utilizando textos de fácil compreensão e seguindo um modelo padronizado. Para isso, haverá normas de regulamentação das autoridades monetárias, estabelecendo termos padrão e variáveis-chave pré-definidas, que permitam ao consumidor precificar e realizar análises comparativas no mercado de forma direta, minimizando a necessidade de consultar especialistas (Barr, 2005; MARQUES, 2010). Exemplo ilustrativo é o caso do crédito (em suas diversas formas), em que o produto ofertado deve ser caracterizado por variáveis-chave como: montante da operação, parcelamento, prazo, taxa de juros anual efetiva, custo efetivo total ao final da operação, além de multa e penalidades para o caso de atrasos, sem dubiedades ou acréscimo de demais taxas. Tais dados comporiam uma matriz síntese e padrão dessa categoria de produto, facilitando comparação do mesmo com os demais disponíveis no mercado.

Essa diretriz é parcialmente contemplada pela lei 8.078, assim como já é recomendada pelas normas do Banco Central do Brasil, embora em termos genéricos, não sistematizados (o que pode ser melhorado pelo PLS 283/PL 3515). Isso se faz necessário pois, conforme apontado por diversas pesquisas empíricas, o descumprimento da lei no país é praticado frequentemente por instituições financeiras (inclusive por grandes bancos), o que requer não apenas legislação, mas um sistema de fiscalização e punição mais rigoroso (IDEC, 2008, 2012a, 2012b, 2012c; Pereira, 2015). Adicionalmente, especialistas recomendam a adoção de lei complementar (incorporada ao texto original do PLS 283) de que as empresas financeiras sejam obrigadas a apresentar uma proposta contratual por escrito ao potencial consumidor de crédito, com validade de dois dias úteis. A vantagem de tal lei (similar à existente na Alemanha) é garantir um prazo mínimo de reflexão, seja para o indivíduo avaliar a necessidade real do crédito, minorando efeito de vieses comportamentais e consumistas, ou seja para poder comparar preços e condições da proposta de crédito com as concorrentes no mercado (Marques, 2010).

A segunda diretriz diz respeito à necessidade de compartilhar minimamente a responsabilidade operacional entre consumidor financeiro e instituição provedora. Isso é importante, pois, se as instituições provedoras não estiverem sujeitas à responsabilização por resultados negativos que podem ocorrer involuntariamente ao consumidor, em consequência 
do consumo de determinado produto financeiro, haverá um evidente conflito de interesses entre as partes. Como citado acima, a empresa busca maximizar vendas de produtos que, entretanto, podem comprometer o bem-estar financeiro dos consumidores ao longo do tempo. Um exemplo são vendas de crédito ao consumidor, associado ao aumento de gastos das famílias que, no limite, podem atingir à condição de superendividamento. Em outros casos, como leasing ou fundos de investimento financeiro atrelados a algum indexador, as vendas podem ser feitas de modo a transferir risco excessivo ao consumidor (como uma maxidesvalorização cambial), que teria aceitado assumir o risco, ancorado na confiança depositada no profissional da instituição provedora (Casado, 2000; Pereira, 2015).

No caso do crédito, a diretriz sustenta que a instituição provedora não pode oferecê-lo sem avaliar previamente a capacidade de pagamento de seu cliente. Embora esse procedimento seja comum em operações de valores mais expressivos, como o crédito imobiliário, o mesmo não ocorre em créditos rotativos, de baixo valor, cuja oferta se dá com maior agilidade, como acontece com o cartão de crédito ou com o crédito consignado, descontado em folha. Entretanto, isso pode se tornar um problema, em caso de uso crescente e repetitivo, com acúmulo expressivo do montante devido. $\mathrm{O}$ resultado é que as famílias podem contrair crédito acima de sua capacidade de pagamento, com efeitos deletérios sobre seu bem-estar financeiro, na forma de multas, penalidades e - no limite - na condição de superendividamento (Dymski, 2007; Pereira, 2015).

Pesquisadores sustentam a necessidade de uma lei de concessão responsável do crédito (similar à legislação vigente na Bélgica, França e África do Sul), para conter o uso de estratégias agressivas de vendas de produtos financeiros. As empresas ofertantes de produtos financeiros seriam, sob tal proposta, responsáveis por apresentar relatórios comprobatórios ao Banco Central que assegurassem a capacidade de pagamento das famílias pelo crédito concedido, a partir do total de dívida já acumulada pela família (em suas diferentes formas), sob pena de serem responsabilizadas por parte do prejuízo financeiro que ocorra após seu uso (condição contemplada no projeto original da PLS 283) (Casado, 2000; Republic of South Africa, 2006). Outra forma alternativa e complementar de lei (em vigor na Bélgica, Luxemburgo e Austrália) é a taxação anual progressiva de instituições provedoras financeiras em relação a taxa de default de sua carteira de clientes. Essa lei operaria como um desincentivo a comportamento mais agressivo por parte das empresas junto a seus clientes com baixa capacidade de pagamento (Mann, 2007).

A terceira diretriz refere-se ao controle do viés comportamental de impulsão e ansiedade do consumidor, explorado pelas instituições atualmente, com possível comprometimento do seu bem-estar financeiro. A ideia, também apresentada por Marques (2010), inspira-se na legislação francesa e estabelece a requisição de um prazo, contado a partir do momento em que um contrato de crédito é assinado, durante o qual o consumidor tem direito de arrependimento, cancelando toda e qualquer operação, sem ônus (além dos juros diários adicionado ao principal recebido) e necessidade de justificativa. Durante tal período, o consumidor refletiria sobre a necessidade do crédito, minorando a ocorrência de operações 
Um plano nacional de capacitação financeira: o caso brasileiro

realizadas por impulso. Atualmente, a lei 8.078 prevê direto de arrependimento, no prazo de sete dias, mas apenas para operações financeiras de crédito e seguros contratadas fora de pontos comerciais (via telefone ou internet), mas esse quadro pode ser corrigido com o PLS 283/PL 3515 .

A quarta diretriz a ser considerada é também a eliminação ou minoração da oferta de incentivos inadequados ao bem-estar financeiro do consumidor. Um exemplo desse incentivo é o utilizado pelas provedoras de cartão de crédito, que oferecem aos clientes: i) benefícios diretos à intensidade do uso do cartão, através de pontos e bonificações, que podem ser revertidos em forma de bônus futuros; ii) possibilidade explícita de pagamento de valor mínimo da fatura do parcelamento do cartão de crédito (15\% da parcela), refinanciando o restante. É sabido que o cartão de crédito oferece várias facilidades para o gasto com consumo, a um custo significativamente elevado de taxa de juros no caso de refinanciamento. Portanto, a aplicação de benefícios e incentivos ilimitados ao uso do cartão de crédito deve ser eliminada pelo Banco Central (Barr; Mullainathan; Shafir, 2008; Warren, 2007).

Finalmente, a quinta diretriz proposta é a introdução de nova lei de falência pessoal, similar à lei em vigor nos EUA e na Europa, para casos de superendividamento passivo, em que não houve responsabilidade intencional. O superendividamento passivo ocorre quando uma família, dado seu atual nível de renda e riqueza, não tem capacidade de cumprir com o pagamento das dívidas acumuladas, referente ao consumo presente e futuro, sem comprometer suas condições básicas de vida (Marques, 2010). Essa incapacidade de pagamento pode decorrer da realização de gastos expressivos de consumo, desproporcionalmente superior à sua condição de vida, constituindo o superendividamento ativo. Por outro lado, pode também ocorrer com famílias de boa-fé que sofreram um ou mais choques de renda (desemprego e queda na renda), riqueza (acidentes ou desastres) e/ou despesa (mortes, divórcio, doenças graves de familiares, dentre outros), que comprometam sua capacidade de pagamento. Este segundo caso constitui o superendividamento passivo, em que a família não foi responsável por sua condição, dada a ocorrência de fatos imprevisíveis (Gloukoviezoff, 2006; Schmidt Neto, 2009; Crocco; Santos; Figueiredo, 2013) ${ }^{3}$.

Inspirada nas experiências internacionais (EUA, Europa e África do Sul) e no próprio PLS 283, a lei proposta se aplicaria aos casos de superendividamento passivo - enquanto o superendividamento ativo seria prevenido pelas diretrizes anteriores. As famílias passivamente superendividadas entrariam em regime de falência pessoal e contariam, após liquidação dos seus bens, com um plano especial de repagamento do restante da dívida, em prazo de até cinco anos, sob supervisão judicial, a contar com: novo parcelamento da dívida; introdução de novo prazo de carência, que reflita sua atual capacidade de pagamento, garantindo um mínimo vital

(3) Não existem dados estatísticos brasileiros para dimensionar o número de famílias superendividadas de forma ativa ou passiva. Estimativa internacionais, apontam que o superendividamento passivo corresponde a maioria nos países avaliados (Gloukoviezoff, 2006). 
Fernando Pereira, Anderson Cavalcante, Marco Crocco

de renda para gastos básicos; possibilidade de obter redução ou isenção parcela referente aos juros, taxas ou, no limite, perdão de todo o montante devido (Marques, 2010).

Resta dizer que a mudança da legislação é apenas condição necessária, que deve vir acompanhada de toda estrutura de fiscalização, supervisão e punição, a fim de torná-la efetiva, a despeito de todo lobby político e poder de mercado das instituições financeiras.

\subsection{Redimensionando a educação financeira}

Conforme exposto, não se pode exigir que pessoas comuns tenham conhecimento técnico aprofundado para lidar com as práticas financeiras relativamente complexas. Deve-se, portanto, reconhecer explicitamente os limites da transferência de conhecimento para impulsionar a capacitação financeira das famílias, evitando a formação de falsas expectativas e a promoção de autoconfiança excessiva, que podem gerar comportamentos financeiros ingênuos.

O objetivo é a que educação financeira trate de uma forma mais ampla os temas da vida financeira familiar em seus diferentes contextos (rural/urbano; centro/periferia; natureza familiar; pobre/rico; inserção no mercado de trabalho, etc.), sem se restringir a ensinamentos de tecnicidades ou ao próprio mercado financeiro.

Dentre os principais aspectos práticos de programas de educação financeira, convém estabelecer alguns princípios. Desde já, assume-se que as iniciativas serão oferecidas de forma gratuita e universal, para garantir acesso a todo cidadão interessado.

Conforme tratado na primeira seção, as atividades de educação financeira deverão ser apresentadas de modo diferenciado (público, conteúdo, pedagogia), para melhor atender a demanda de distintos segmentos de participantes, o que tende a garantir maior motivação dentre os participantes e um resultado mais efetivo. A metodologia pedagógica utilizada deve ser ampla, não apenas através de aulas expositivas, seminários e palestras, mas fazendo uso de apresentações lúdicas, teatros e jogos interativos (presencial e complementada por outras formas de mídia e redes sociais), que melhor atendam ao perfil socioeconômico e cultural de cada nicho demográfico.

O nível do conteúdo geral ensinado deverá ser básico, envolvendo conceitos, relações causais fundamentais, aspectos práticos e descrição de fontes de dados econômicos públicos que mais se apliquem às finanças pessoais (conteúdo direcionado, conforme o caso). Além disso, deverão ser apresentados alertas referentes aos riscos do uso de crédito, do (super)endividamento, das euforias do mercado, do conflito de interesses e da ilusão do marketing publicitário (e a exploração de vieses comportamentais), indicando noções da percepção da existência da incerteza e da adoção de um comportamento planejador e precaucional por parte dos participantes. Deverão ser apresentadas noções de direito do consumidor financeiro, assim como a divulgação do aparato legal existente (como a CDC) e de acesso ao sistema de proteção ao consumidor (Procon/Ministério da Justiça e Ministério da 
Um plano nacional de capacitação financeira: o caso brasileiro

Previdência Social). Da mesma forma, haverá direcionamento para profissionais dos centros públicos de aconselhamento financeiro (tratados na sequência), em caso de questões de maior complexidade.

A participação da população adulta deverá ser voluntária (ainda que possa vir a ser recomendada a determinados nichos) e segmentada, para assegurar maior motivação dentre os participantes. No caso específico da população assalariada, deve haver incentivo aos empregadores, entidades empresariais ou de classe em promover seminários sobre temas de contribuição previdenciária. A população em idade escolar, por sua vez, será apresentada a itens de educação formal, sem necessitar a oferta de uma disciplina exclusiva neste tema, caso se considere impraticável uma mudança mais profunda na atual grade curricular.

Antecedendo a realização do plano nacional, haverá um mapeamento das iniciativas gratuitas de educação financeira vigentes no país, executadas por diferentes institutos e órgãos, que possam ser incorporados ao plano (desde que atendam as diretrizes), uma ação similar à que vem sendo executada no país segundo o esforço da Enef. As iniciativas devem prever a montagem de base de dados interna, que opere como insumo para estudos de avaliação e monitoramento ao longo do tempo.

Deve-se conduzir uma pesquisa de intenções para avaliar qual a dimensão da população adulta que efetivamente demandará participação nas atividades previstas. Adicionalmente, as iniciativas serão oferecidas de forma contínua, contemplando repetição por parte dos participantes, embora não estejam previstas atualizações significativas em curtos intervalos de tempo.

A proposta é que os profissionais educadores tenham ensino médio e sejam especializados em cursos de finanças pessoais, cujo treinamento pode ocorrer em parceria com universidades públicas, entidades financeiras e do terceiro setor, sob supervisão do órgão público responsável pelo plano nacional ${ }^{4}$. Finalmente, o financiamento global desconsiderando parcerias com o treinamento - deve se dar pelo orçamento público, parte desse coberto através de impostos sobre lucros das instituições financeiras.

\subsection{Os centros públicos de aconselhamento financeiro}

Para orientar a população a lidar com problemas práticos de decisão financeira, sem enfrentar conflito de interesses, a proposta é a montagem de uma estrutura ampla de centros públicos de aconselhamento financeiro (CPAF), com atendimento prestado por consultores independentes (CFI).

O atendimento deve ser disponibilizado de forma universal, com previsão de acompanhamento e supervisão nos casos mais complexos. Apesar de universal, o foco deste serviço deve ser a população de baixa renda, que tende a ter maior demanda reprimida por

(4) As entidades parceiras (das esferas públicas, privadas e do terceiro setor) receberão um selo oficial de patrocinador da educação financeira e terão direito a explorar uso publicitário do mesmo, a fim de estimulá-las. 
serviço qualificado de consultoria provida pelas instituições de mercado (Kempson; Collard, 2012; Money Advice Service, 2015).

Considerando o histórico de iniciativas empíricas e propostas presentes na literatura especializada (Pereira, 2015), entende-se que os centros deverão estar preparados para abranger os seguintes temas: i) produtos e serviços financeiros disponíveis; ii) informações sobre o mercado imobiliário e de ativos reais; iii) planejamento e análise comparativa, para atender a eventos do ciclo de vida familiar e poupança precaucional; iv) orientação financeira de microempreendimentos populares (abertura, venda e fechamento de atividade; tributos); v) gerenciamento de crises financeiras pessoais (perda de emprego, queda na renda, despejo da moradia, falecimento e doenças graves) e superendividamento; vi) apontamentos sobre questões tributárias e direitos do consumidor financeiro e; vii) redirecionamento a outros profissionais especializados.

O consultor deve ter o cuidado de não criar falsas expectativas junto ao público. Assim, ao tratar de temas futuros, deve-se ressaltar fundamentos do risco não calculável e dos vieses comportamentais mais comuns, deixando o público ciente de que não existem respostas completas que antecipem corretamente o desempenho futuro da economia, mas apenas tendências que podem sofrer alterações. Em especial nos períodos expansivos do ciclo econômico, o consultor deve assumir um posicionamento claro que aponte os riscos de reversão do ciclo, assim como a importância de um comportamento precaucional por parte das famílias, evitando climas de euforia de mercado.

Os CFI devem ser profissionais especializados em finanças pessoais, com formação superior (no caso do consultor sênior) ou no ensino médio (consultor assistente), e que conte não apenas com conhecimento e habilidade técnica, mas com informações econômicas e financeiras atualizadas. Os profissionais devem ser capazes de se expressar em linguagem apropriada para tratamento de um público médio de baixo nível educacional e conhecimento precário em finanças.

Assim como no caso da educação financeira, é indispensável a realização de estudos empíricos mais detalhados sobre a dimensão e o perfil da demanda. O mesmo ocorre com a construção de um banco de dados para subsidiar estudos de monitoramento e avaliação das atividades prestadas.

Por fim, entende-se que a maior parte do financiamento deve vir de impostos cobrados sobre lucros das instituições financeiras, como apontado em projetos internacionais (HASSAN et al., 2008).

\subsection{Estrutura operacional do PNCF e uma estimativa orçamentária preliminar}

Conforme já exposto, o PNCF proposto tem como objeto o atendimento de todo cidadão. A natureza desse atendimento, no entanto, irá variar: para a população em idade 
Um plano nacional de capacitação financeira: o caso brasileiro

escolar, o foco é a oferta de educação financeira, enquanto para toda população adulta prevêse também a disponibilização de serviços de aconselhamento financeiro.

A justificativa para a oferta de serviço universal de aconselhamento financeiro para os adultos é que estes, como cidadãos ativos, possuem uma vida financeira (ainda que não na condição de consumidores diretos das instituições do mercado financeiro). Portanto, são potenciais demandantes de um serviço de aconselhamento. Nesse aspecto, o objetivo do plano proposto é prestar o serviço não apenas para a população financeiramente incluída, mas para os excluídos do mercado financeiro, uma vez que estes também tomam decisões financeiras que podem assumir natureza relativamente complexa. $\mathrm{O}$ foco do plano, por sinal, deve ser o favorecimento da população relativamente mais pobre, que tem acesso mais precário (ou são totalmente excluídos do acesso) aos serviços de atendimento prestados pelas instituições financeiras de mercado.

A estimativa de orçamento do PNCF apresentada a seguir deve ser considerada apenas um esforço preliminar, a requerer, na prática, um tratamento mais profundo e sistemático no caso efetivo de sua implementação. A atual estimativa, porém, constitui-se um guia útil para a própria justificativa política da proposta junto à sociedade.

O cálculo orçamentário foi feito da seguinte forma: os centros públicos de aconselhamento financeiro (CPAF) - que também seriam responsáveis pela realização de atividades intermitentes de educação financeira para os adultos - ocupariam instalações dos Centros de Referência de Assistência Social (CRAS). Essa medida garantiria maior capilaridade ao PNCF (quase a totalidade de municípios seriam atendidos) e sua presença em um instrumento público localizado em áreas povoadas pelos mais pobres.

Segundo a proposta, o número de CPAF vai depender do tamanho da população municipal, de modo que a cada faixa de até 50 mil habitantes haverá um CPAF, delimitado pelo respectivo número de $\mathrm{CRAS}^{5}$. Como resultado, estariam atualmente em operação $7.202 \mathrm{CPAF}$, espalhados por 5.503 municípios $^{6}$.

Cada CPAF contaria com uma equipe composta por um consultor financeiro sênior e dois consultores assistentes, todos na condição de funcionários públicos, recebendo salários mensais de, respectivamente, $\mathrm{R} \$ 4$ mil e $\mathrm{R} \$ 2$ mil - valores estabelecidos com base em concursos públicos para profissionais com perfis similares. As equipes estariam devidamente equipadas por instrumentos de trabalho, conforme demonstrado na Tabela 1 anexa. Isso resultaria em um custo anual aproximado de $\mathrm{R} \$ 1,12$ bilhão, o que incluiria - além de gastos com salários, encargos, móveis, equipamentos e materiais - um valor referente a cursos específicos para formação/atualização dos próprios consultores/educadores (maiores detalhes na Tabela 1 anexa). Uma vez em funcionamento, esse montante seria melhor apurado, com análises de avaliação e monitoramento, responsáveis pelo dimensionamento dos pontos de

(5) Em um exemplo simples, um município de 130 mil habitantes teria três CPAF, caso disponha três ou mais CRAS.

(6) Dados do Censo CRAS 2015 apontam a existência de 8.155 unidades. Disponível em: http://www.mds.gov.br. 
maior demanda pelo serviço, considerando necessidades e possibilidades de expansão. Em resumo, esta é a proposta de estrutura operacional do PNCF, acompanhado pela estimativa orçamentária.

Antes do encerramento da seção, uma natural comparação deve ser feita entre o PNCF proposto e a vigente Estratégia Nacional de Educação Financeira (Enef), cujo aporte de valores previstos para o triênio 2013-2015 se limitava a R \$ 8,5 milhões (Brasil, 2013). Dito de outra forma, ainda que a Enef brasileira foque apenas em ações de educação financeira, é difícil pensar que esse tipo de ação possa alcançar resultados substantivos em uma dimensão tão restrita ${ }^{7}$.

\section{Conclusões}

Este artigo apresentou uma proposta de um plano nacional de capacitação financeira das famílias brasileiras, com base nos fundamentos teóricos da abordagem crítica institucionalista, assim como em determinados aspectos práticos e no histórico acumulado pela literatura.

O diferencial do plano nacional proposto é o foco sobre todo o ambiente socioeconômico no qual as pessoas estão inseridas, incluindo o sistema financeiro. Assim, o plano não se restringe ao tratamento do processo de decisão financeira individual abstrata (como tratado pela abordagem convencional e seguida pelos formuladores da Enef), mas também da relação deste indivíduo, em seu contexto socioeconômico, com todo o sistema financeiro, desde as instituições ofertantes ao aparato de regulamentação e defesa e proteção do consumidor financeiro.

O primeiro elemento é a reforma da regulamentação do sistema de proteção e defesa do consumidor financeiro. Ciente das limitações do consumidor financeiro típico, as diretrizes propostas buscam minimizar a exploração, por parte das instituições provedoras financeiras, de vieses comportamentais prejudiciais ao bem-estar financeiro, além de propor um tratamento minimamente adequado à condição de superendividamento.

A educação financeira é tratada pelo plano nacional em uma dimensão relativamente modesta, que melhor reflete seu efetivo potencial. Sua função é nivelar conhecimentos financeiros básicos, incorporando noções de incertezas relacionadas às práticas financeiras e de potenciais conflitos de interesses entre provedores e consumidores. Além disso, a educação

(7) O debate sobre se o valor total orçado para o PNCF é politicamente viável deve ser feito publicamente com a sociedade. No entanto, alguns valores relativos são ilustrativos e devem ser considerados. Segundo estudo do Dieese, os gastos anuais com publicidades dos cinco maiores bancos nacionais de varejo oscilaram entre $\mathrm{R} \$ 3,5$ bi e $\mathrm{R} \$ 4$ bi no período 2011-2015 (portanto, montantes quase quatro vezes superiores ao proposto para o PNCF), o que dimensionam o poder das instituições financeiras em influenciar o comportamento dos consumidores. Adicionalmente, com base no demonstrativo de resultados publicados no Banco Central, o orçamento do PNCF corresponde a 0,93\% do lucro líquido dos conglomerados financeiros e instituições independentes de 2016. 
Um plano nacional de capacitação financeira: o caso brasileiro

financeira deve divulgar aspetos institucionais de acesso aos centros de aconselhamento financeiro, assim como do sistema de proteção e defesa do consumidor financeiro.

$\mathrm{O}$ aconselhamento financeiro será oferecido por consultores qualificados e independentes para orientar a população a lidar com problemas efetivos, o que abrange desde o provimento de informações financeiras gerais até serviços mais sofisticados de orientação e supervisão das famílias superendividadas. Assim como os educadores, os consultores devem evitar a criação de falsas expectativas junto ao público, apontando fundamentos de vieses behavioristas e da incerteza fundamental que afetam, em conjunto, as decisões pessoais e a economia como um todo. Os centros de aconselhamento (CPAF) - localizados junto ao CRAS - devem representar a principal fonte de informações e conselhos financeiros sobre finanças pessoais, especialmente para um público que não dispõe de serviço similar qualificado por parte das instituições financeiras, garantindo certa neutralidade aos interesses de mercado.

\section{Bibliografia}

BARR, M. S. Modes of credit market regulation. In: RETSINAS, N. P.; BELSK, E. S. (Org.). Building assets, building wealth: creating wealth in low-income communities. Washington: Brooking Press, 2005. p. 1-51.

BARR, M. S.; MULLAINATHAN, S.; SHAFIR, E. Behaviorally informed financial services regulation. Washington: New America Foundation, 2008.

BRASIL. Brasil: Implementando a Estratégia Nacional de Educação Financeira. Documento elaborado pelo Conselho Nacional de Educação Financeira - Conef (2013). Disponível em: https://www.bcb.gov.br/pre/pef/port/Estrategia_Nacional_Educacao_Financeira_ENEF.pdf.

Acesso em: 2 out. 2017.

BRAUNSTEIN, S.; WELCH, C. Financial literacy: an overview of practice, research, and policy. Federal Reserve Bulletin, v. 88, p. 445-457, Nov. 2002.

CAIN, D. M.; LOEWENSTEIN, G.; MOORE, D. A. The dirt on coming clean: perverse effects of disclosing conflicts of interest. Journal of Legal Studies, v. 34, p. 1-25, Jan. 2005.

CASADO, M. M. Proteção do consumidor de crédito bancário e financeiro. São Paulo: Ed. Revista dos Tribunais, 2000.

CONSUMER FINANCIAL PROTECTION BUREAU. Financial well-being: the goal of financial education. Iowa: CFPB, 2015.

COUTINHO, L.; BELLUZZO, L. G. 'Financeirização' da riqueza, inflação de ativos e decisões de gastos em economias abertas. In: FERRARI FILHO, F.; PAULA, L.F. (Org.). Globalização financeira: ensaios de macroeconomia aberta. Petrópolis: Editora Vozes, 2004. p. 59-77.

CROCCO, M. A.; SANTOS, F.; FIGUEIREDO, A. Exclusão financeira no Brasil: uma análise regional exploratória. Revista de Economia Política, São Paulo, v. 33, n. 132, p. 505-526, 2013. 
Fernando Pereira, Anderson Cavalcante, Marco Crocco

DYMSKI, G. A. Exclusão e eficiência: a transformação global do core banking, um estudo de caso sobre o Brasil. In: PAULA, L. F.; OREIRO, J. L. (Org.). Sistema Financeiro - uma análise do setor bancário brasileiro. Rio de Janeiro: Elsevier, 2007. p. 255-283.

FINANCIAL SERVICES AUTHORITY. Measuring financial capability: an exploratory study. Consumer Research, London: FSA, n. 37, 2005.

FROUD, J. et al. Escaping the tyranny of earned income? The failure of finance as social innovation. Manchester: University of Manchester, Mar. 2009. (n. 66).

GLOUKOVIEZOFF, G. From financial exclusion to overindebtedness: the Paradox of difficulties for people on low income? In: ANDERLONI, L.; BRAGA, M. D.; CARLUCCIO, E. M. (Org.). New frontiers in banking services: emerging needs and tailored products for untapped markets. Berlim: Springer, 2006. p. 213-245.

GUÉRIN, I. Households' over-indebtedness and the fallacy of financial education: insights from economic anthropology. Paris: Microfinance in Crisis, 2012. (Working Paper, n. 1).

HASSAN, N. et al. Delivering money advice in South Africa: study into the provision of money advice to low-income persons. Johannesburg: Genesis Analytics, 2008.

HM TREASURY. Financial capability: the Government's long-term approach. London: HMSO, 2007.

IDEC. Início conturbado. Revista do IDEC, p. 16-20, mar. 2012a.

IDEC. Mais caro do que parece. Revista do IDEC, jun. 2012b.

IDEC. Superendividamento no Brasil. São Paulo: IDEC, 2008.

IDEC. Tudo na mesma. Revista do IDEC, p. 24-27, set. 2012c.

JANUSZ, T. Kickback: confessions of a mortgage salesman. Tennesse: Insight Publishing, 2006.

KAHNEMAN, D.; TVERSKY, A. Prospect theory: an analysis of decision under risk. Econometrica, v. 47, n. 2, p. 263-292, 1979.

KEMPSON, E.; ATKINSON, A.; PILLEY, O. Policy level response to financial exclusion in developed economies: lessons for developing countries. Bristol: Department for International Development (DFID), 2004. p. 49.

KEMPSON, E.; COLLARD, S. Developing a vision for financial inclusion. 1. ed. Surrey: Friends Provident Foundation, 2012.

LUSARDI, A. Financial literacy: an essential tool for informed consumer choice? [manuscrito], 2008. Disponível em: http://www.dartmouth.edu/ alusardi/Papers/ Lusardi_Informed_Consumer.pdf. Acesso em: 20 ago. 2016. 
Um plano nacional de capacitação financeira: o caso brasileiro

LUSARDI, A.; MICHAUD, P.; MITCHELL, O. S. Optimal financial knowledge and wealth inequality. Cambridge, MA: NBER, 2013. (Working Paper., n. 18669).

MANN, R. J. Charging ahead: the growth and regulation of payment card markets. New York: Cambridge University Press, 2007.

MARQUES, C. L. Fundamentos científicos da prevenção e tratamento do superendividamento. Caderno de Investigaçoes Científicas, Brasília, Ministério da Justiça, 2010.

MEZA, D.; IRLENBUSCH, B.; REYNIERS, D. Financial capability: a behavioural economics perspective. London: FSA, 2008. (Consumer Research., n. 69).

MONEY ADVICE SERVICE - MAS. Review of the Money Advice Service. London: MAS, 2015.

O'CONNELL, A. How effective is financial education? Policy Quarterly, v. 3, n. 3, p. 40-46, 2007.

OECD. Improving financial literacy: analysis of issues and policies. Paris: Organization for Economic Cooperation and Development, 2005.

PEREIRA, F. B. Notas de um plano nacional de capacitação financeira. 2015. Tese (Doutoramento em Economia)-Cedeplar, Universidade Federal de Minas Gerais, 2015.

REPUBLIC OF SOUTH AFRICA. National Credit Act n. 34 of 2005. Government Gazette, South Africa, n. 28619, 2005.

RUSSIA'S G20 PRESIDENCY; OECD. Advancing national strategies for financial education. Paris: OECD, 2013.

SANTOS, A. C. Financial literacy, financialisation and neoliberalism. Finance and wellbeing. Leeds: Fessud, 2013. (Working Paper Series, n. 11).

SCHMIDT NETO, A. P. Superendividamento do consumidor: conceito, pressupostos e classificação. Revista da SJRJ, v. 16, n. 26, p. 167-184, 2009.

SERVON, L. J.; KAESTNER, R. Consumer financial literacy and the impact of online banking on the financial behavior of lower-income bank customers. Journal of Consumer Affairs, v. 42, n. 2, p. 271-305, 28 jun. 2008.

SHERRADEN, M. S. Financial capability: what is it, and how can it be created? St. Louis: Washington University, 2010. (Working Papers, n. 10-17).

SLOVIC, P.; FISCHHOFF, B.; LICHTENSTEIN, S. Facts versus fears: understanding perceived risk. In: KAHNEMAN, D.; SLOVIC, P.; TVERSKY, A. (Org.). Judgment under uncertainty: heuristics and biases. Cambridge: Cambridge University Press, 2001. p. 463-489. 
Fernando Pereira, Anderson Cavalcante, Marco Crocco

TEIXEIRA, A.; TABAK, B.; CAJUEIRO, D. Finanças Comportamentais: aversão míope às perdas e efeito dinheiro em casa. In: ÁVILA, F.; BIANCHI, A. M. (Org.). Guia de economia comportamental e experimental. São Paulo: EconomiaComportamental.org, 2015. p. 200-209.

THORESEN, O. Thoresen review of generic financial advice: final report. London: HM Treasury, 2008.

U.S. DEPARTMENT OF TREASURY. President's Advisory Council on financial capability: final report. Washington, DC: [s.n.], 2013.

WARREN, E. Unsafe at any rate. Democracy: A Journal of Ideas, n. 5, p. 8-19, 2007.

WILLIS, L. E. Against financial literacy education. Iowa Law Review, v. 94, p. 197, 2008.

WORLD BANK. Making sense of financial capability surveys around the world: a review of existing financial capability and literacy measurement instruments. Washington, DC: World Bank, 2013. 


\section{Anexo}

Tabela 1

Orçamento anual estimado para o Plano Nacional de Capacitação Financeira (2017)

\begin{tabular}{l|c|c}
\multicolumn{1}{c|}{ Itens de custo } & Mensal & Anual \\
\hline Consultor Sênior & $\mathrm{R} \$ 6.065,00$ & $\mathrm{R} \$ 72.780,00$ \\
\hline Consultores Assistentes & $\mathrm{R} \$ 6.190,00$ & $\mathrm{R} \$ 74.280,00$ \\
\hline Depreciação: 2 PC + 1 notebook & & $\mathrm{R} \$ 1.700,00$ \\
\hline Depreciação: 4 cadeiras + 1 mesa & & $\mathrm{R} \$ 150,00$ \\
\hline Depreciação: Telefones & & $\mathrm{R} \$ 333,33$ \\
\hline Custo de linhas telefônicas & & $\mathrm{R} \$ 2.400,00$ \\
\hline Outros materiais & & $\mathrm{R} \$ 2.000,00$ \\
\hline Total por CPAF $\$ 153.643,33$ \\
\hline Subtotal: 7202 CPAF & $\mathrm{R} \$ 12.803,61$ & $\mathrm{R} \$ 1.106 .539 .286,67$ \\
\hline $\begin{array}{l}\text { Adicional (custos de formação dos } \\
\text { consultores/ educadores) }\end{array}$ & $\mathrm{R} \$ 92.211 .607,22$ & $\mathrm{R} \$ 15.000 .000,00$ \\
\hline Total & & $\mathrm{R} \$ 1.121 .539 .286,67$ \\
\hline
\end{tabular}

Fonte: Elaboração própria. 